\title{
Análise de similaridade entre os setores empresariais beneficiados pelo programa Subvenção Econômica à Inovação
}

\author{
Gabriel Alves de Pinho* \\ Rogério Gomes $^{* *}$
}

\section{Resumo}

Este presente artigo visa examinar as possíveis similaridades entre os setores empresariais beneficiados pelos recursos oriundos dos editais de Subvenção Econômica à Inovação - FINEP primeiramente por uma análise descritiva dos dados seguido da metodologia de cluster hierárquico segundo Método de Ward. Os resultados obtidos foram a presença de maior homogeneidade entre os grupos de alta intensidade tecnológica, predominantes tanto na quantidade quanto no volume de recursos alocados e demandados. As conclusões apontam para um maior detalhamento nos editais para atender as especificidades das empresas e maior integração com as outras modalidades de financiamento, especialmente para as micro e pequenas empresas.

Palavras-chave: Subvenção Econômica, Inovação, FINEP, cluster.

\section{Abstract}

This paper aims at examining the possible similarities among business sectors benefiting from the resources from Economic Subvention (FINEP), from a descriptive statistics followed by the hierarchical cluster methodology via Ward's Method. The results obtained were the presence of greater homogeneity between groups of higher technological intensity, both in the quantity and in the volume of resources allocated and demanded. Conclusion points to a greater detail in the calls for proposals to meet the specificities of companies and greater integration with other financing modalities, especially for micro and small enterprises.

Keywords: Economic Subvention, Innovation, FINEP, cluster.

\section{Introdução}

A inovação tecnológica é um dos fenômenos centrais para a constante transformação e desenvolvimento do sistema econômico. Com a descoberta e a exploração de novos produtos,

\footnotetext{
*Universidade Estadual de Campinas - IE/UNICAMP. E-mail: pinho.gabriel@ globomail.com

***Universidade Estadual Paulista Júlio de Mesquita Filho - FCLAr/UNESP. E-mail: rgomes@ fclar.unesp.br
} 
processos ou serviços, a atividade inovativa torna-se altamente dispendiosa e, em algumas etapas, com elevado grau de incerteza (PAVITT, 2005).

Nesse cenário, em que a decisão de investir em inovação significa assumir grandes riscos frente à incerteza ${ }^{1}$, as políticas públicas de financiamento à inovação apresentam-se como uma prática amplamente realizada em diversos países, cujo objetivo é potencializar a capacidade tecnológica e, portanto, estimular os investimentos privados, além de estabelecer um ambiente institucional propício para a promoção de interações entre diversos agentes, como empresas, universidades e institutos de pesquisa (AVELLAR \& BITTENCOURT, 2017).

Para isso, as políticas de financiamento à inovação devem desempenhar dois papeis fundamentais: a) incentivar o estabelecimento e ampliação dos esforços inovativos e dos gastos em P\&D das empresas; e b) realizar atividades de suporte à inovação, como aprimoramento da infraestrutura tecnológica, capacitação de recursos humanos altamente especializados e criação de vínculos entre os agentes que compõe esse sistema (CEPAL, 2004). Em virtude disso, os objetivos da política podem variar de acordo com o enfoque dado, seja no desempenho de empresas ou de um setor em específico, seja em estimular parcerias entre empresas e institutos de pesquisa, em programas de qualidade ou melhorias do ambiente institucional.

As políticas de financiamento à inovação no Brasil passaram a inserir gradativamente a pauta da inovação em seus planos plurianuais somente a partir do fim da década de 90, com a criação dos fundos setoriais, a fim de captar maior volume de recursos e estabelecimento de fundos para a Ciência e Tecnologia (C\&T) no Brasil, e também estimular a interação entre centros de pesquisa e empresas. Nos anos 2000, o governo brasileiro incorporou outros instrumentos de incentivo ao esforço inovativo das empresas - como a Lei de Inovação (Lei $n^{\circ}$ 10.973/2004) e a Lei do Bem (Lei $n^{\circ} 11.196 / 2005$ ) - visando estabelecer linhas gerais de incentivos e fomento à pesquisa, desenvolvimento e inovação tecnológica (P, D \& I) no país (DE NEGRI et.al., 2009; HOLLANDA, 2010; MCTI, 2013; MIRANDA \& MIRRA, 2012).

\footnotetext{
${ }^{1} \mathrm{~A}$ incerteza pode estar associada a razões técnica, à complexidade inerente ao processo (que pode envolver variáveis e agentes diversos), ou até mesmo por questões relativas ao mercado e aos negócios (pelo viés macroeconômico). No agregado, essas características impossibilitam a capacidade de estimar ex-ante a rentabilidade dos investimentos em inovação. Assim, de maneira geral, os esforços em Pesquisa e Desenvolvimento $(\mathrm{P} \& \mathrm{D})$ revelam relação inversa com as incertezas inerentes, isto é, quanto maior a incerteza, menor a propensão a investimentos em P\&D (BAKKER, 2013; CAVALCANTE et. al, 2017; FREEMAN \& SOETE, 1997; RAPINI, 2009;).
} 
Dentre vários instrumentos públicos de estímulo à inovação das empresas, o programa de Subvenção Econômica tem duas formas de atuação: destinar recursos para cobertura de despesas e custeios das atividades de inovação, como também ressarcimento de parte da remuneração de pesquisadores titulados a serem contratados pelas empresas (FINEP, 2010).

Para analisar tal atuação, os estudos empíricos procuraram examinar o programa de Subvenção Econômica à Inovação (COSTA et al., 2013), setores específicos e portes empresariais (BORGES \& HOFFMAN, 2017) beneficiados pelos editais, assim como a cooperação tecnológica entre universidades e pequenas empresas (CARRIJO \& BOTELHO, 2013 ) inseridos no programa.

A fim de adicionar elementos para o debate, este artigo procura examinar as possíveis similaridades entre os setores empresariais beneficiados pelos recursos oriundos dos editais de Subvenção Econômica à Inovação - FINEP², através da metodologia de cluster. Para isso, o trabalho é dividido em mais 3 seções. O primeiro item descreve brevemente os editais de Subvenção Econômica publicados pela agência financiadora, desde o seu primeiro ano de lançamento em 2006 até os editais temáticos de 2013. O segundo item trará o instrumental metodológico por uma análise descritiva dos dados seguido da metodologia de cluster hierárquico por Método de Ward e seus respectivos resultados. Por fim, no último item são feitas algumas considerações sobre os resultados encontrados e as implicações destes para o programa.

\section{Subvenção Econômica à Inovação: breve apresentação}

Como apresentado anteriormente, a política de apoio à inovação tem ganhado, nos últimos anos, destaque na agenda governamental dos países, sejam emergentes ou desenvolvidos. No Brasil, pode-se observar os esforços do governo por meio da implementação das Leis de Inovação, com o objetivo de gerar incentivos à Ciência, Tecnologia e Inovação (CT\&I); e do Bem, estabelecendo os incentivos fiscais às atividades inovativas.

A Lei de Inovação ( $n^{\circ}$ 10.973/2004) sustenta-se em três principais eixos: i) estabelecimento de um ambiente favorável a parcerias estratégicas entre institutos tecnológicos,

\footnotetext{
${ }^{2}$ Os autores agradecem à FINEP, especialmente Delci Souza e Oswaldo Cantini, pelo apoio e fornecimento do banco de dados.
} 
universidades e empresas; ii) incentivo à participação de instituições de Ciência e Tecnologia (C\&T) no processo de inovação; iii) promoção à inovação tecnológica nas empresas.

Por sua vez, a Lei do Bem ( $\left.{ }^{\circ} 11.196 / 2005\right)$ estabeleceu a subvenção econômica para as empresas, instrumentos legais para incubação de empresas em espaço público e criou regras para a participação de pesquisadores públicos nos processos de inovação tecnológica no setor produtivo.

Diante destas iniciativas, observou-se o aumento do número de empresas inovadoras que participam em pelo menos uma das modalidades de financiamento público à inovação, de 18,8\% (2003-2005) para 22,3\%, no período de 2009 a 2011 (AVELLAR \& BITTENCOURT, 2017). A FINEP é uma das principais instituições públicas, vinculada ao MCTIC (Ministério da Ciência, Tecnologia, Inovações e Comunicações), responsável por esses incentivos financeiros à inovação nas empresas, que, por sua vez, têm ampliado ao longo dos anos, seja por meio de editais públicos - para recursos não reembolsáveis (subvenção econômica) às empresas e interação entre estas e universidades e institutos de pesquisa (PAPPE) - seja por recursos reembolsáveis via taxas de juros subsidiadas (Juro Zero).

A subvenção econômica à inovação, instituída com outras modalidades de financiamento público para o desenvolvimento tecnológico e à difusão do conhecimento gerado nas universidades e em centros de pesquisa em apoio a inovações no setor produtivo. Os recursos são provenientes dos fundos setoriais de ciência e tecnologia, respondendo diretamente ao Fundo Nacional de Desenvolvimento Científico e Tecnológico (FNDCT), onde a FINEP atua como Secretaria Executiva. O destino de recursos de subvenção econômica não possui limitações quanto ao porte setorial da empresa beneficiária, mas há uma parcela mínima de $40 \%{ }^{3}$ do total de recursos para aplicação em micro e pequenas empresas (MPEs).

Os temas/setores selecionados para a aprovação dos projetos nos editais de 2007 a 2010 foram: tecnologia da informação e comunicação (TICs), biotecnologia, saúde, defesa e segurança pública, energia e desenvolvimento social. Durante este período, com valor aprovado de mais de $\mathrm{R} \$ 1,5$ bilhão para as áreas, houve uma certa constância no aporte à Biotecnologia e Saúde, TICs, Defesa e Segurança Pública. Outro fator que corrobora para o aspecto da

\footnotetext{
${ }^{3}$ A mudança ocorreu a partir do edital de 2007, passando de 20\% (em 2006) para 40\%. Deduz-se que, a partir desta decisão, a agência notou que o instrumento é especialmente adequado para atender às necessidades das empresas de menor porte, pois estas possuem maiores dificuldades para acessar outras fontes de financiamento para seus projetos (CGEE e ANPEI, 2009).
} 
continuidade está na orientação ${ }^{4}$ para atender às necessidades das empresas de menor porte, cujos canais de acesso a outras formas de financiamento são, de certa maneira, reduzidos (CGEE \& ANPEI, 2009; RAPINI, 2010).

Com base nos programas prioritários da Estratégia Nacional de Ciência, Tecnologia e Inovação (ENCTI), a FINEP definiu, para execução de sua Política Operacional de 2012 a 2014, praticamente os mesmos temas prioritários dos editais anteriores, com exceções para: Defesa e Aeroespacial; Petróleo e Gás; e Tecnologia Assistiva. Além disso, a agência passou a priorizar as microempresas, pequenas empresas e empresas de pequeno porte por meio das operações descentralizadas, e tecnologias voltadas ao desenvolvimento de produtos e processos sustentáveis (FINEP, 2013).

A partir do edital de Tecnologia Assistiva, todas as seleções públicas da Finep passaram a ser temáticas, ou seja, cada edital seria destinado a um único tema em específico, sendo estas de acordo com o alinhamento das políticas públicas em vigência: TI Maior, Construção Sustentável e Saneamento Ambiental, Nanotecnologia ${ }^{5}$ e Processos Biotecnológicos. Os editais deste período tiveram aproximadamente $\mathrm{R} \$ 540$ milhões alocados em 132 projetos das áreas contempladas.

Por fim, o último edital lançado, em 2015 (até 2017) foi uma seleção públicas destinado às empresas das áreas de Energia e Nanotecnologia que atendessem a demanda estabelecida no acordo entre a FINEP e a Agência Espacial Brasileira (AEB) para transferência tecnológica no âmbito aeroespacial. 5 empresas foram selecionadas, com recursos totais liberados de aproximadamente $\mathrm{R} \$ 22,5$ milhões.

De maneira geral, pode-se observar que a FINEP manteve critérios ${ }^{6}$ e ranqueamento dos projetos propostos em boa parte de seus editais lançados: capacidade técnica da empresa executora, grau de inovação dos projetos em relação às soluções existentes e impacto esperado

\footnotetext{
${ }^{4}$ Essa orientação, proveniente de mudanças ocorridas a partir do edital de 2010, trouxe uma maior demanda das empresas de médio porte pela subvenção econômica, que chegou a quase $25 \%$ do total de projetos. Em média, houve um aumento de $10 \%$ se comparados aos resultados dos editais anteriores. Mesmo com esse resultado positivo das empresas de médio porte e com aumento da contrapartida a ser aportada pelas empresas de menor porte, as MPEs prevaleceram tanto na quantidade total de projetos (70\%) quanto no montante dos recursos ( $\mathrm{R} \$ 145,2$ milhões).

${ }^{5}$ Importante destacar que o edital de Nanotecnologia foi o primeiro a contemplar áreas industriais de baixa intensidade tecnológica, posto que os editais anteriores atribuíram a nanotecnologia às áreas de maior conteúdo tecnológico (FINEP, 2014).

${ }^{6}$ A partir do edital de 2007, eliminou-se a menção feita na chamada pública do ano anterior a respeito do compartilhamento de custos, com diminuição do risco tecnológico, em prol de uma formulação mais genérica de "apoiar o desenvolvimento de processos e produtos inovadores em empresas" (CGEE e Anpei, 2009).
} 
da inovação no país. Os editais lançados entre 2006 e 2010 apresentavam uma importante regulamentação: $30 \%$ dos recursos disponíveis eram alocados em empresas brasileiras situadas nas regiões Norte, Nordeste e Centro-Oeste. A justificativa era de que essas empresas apresentavam altas taxas de mortalidade, se comparadas às demais regiões do país (HOLLANDA, 2010). Se, por um lado, disseminar os polos inovação em âmbito nacional é uma política desejável, por outro, essa atividade requer recursos financeiros e tempo para acumular conhecimento e capacitações que, por vezes, limitam a sua duplicação. Em suma, há um trade-off entre dispersar e concentrar tais atividades.

Quanto aos aportes dados através dos editais e das políticas vigentes, pode-se observar uma relativa constância no apoio às áreas de Biotecnologia e Saúde, TICs e Defesa e Segurança Pública, demonstrando que esse instrumento de financiamento realiza esforços para alinhar as prioridades estabelecidas nas seleções públicas com as diretrizes das políticas de C, T\&I.

Para compreender melhor essa constância de apoio às áreas "portadoras de futuro", segundo termo estabelecido na Política Industrial, Tecnológica e de Comércio Exterior (PITCE), é preciso também identificar as similaridades entre os setores beneficiários do programa de Subvenção Econômica e, desta forma, inferir sobre desdobramentos para editais futuros.

A hipótese levantada para averiguar as similaridades baseia-se em dois pilares: i) as empresas beneficiadas pelo programa de Subvenção Econômica apresentam heterogeneidade significativa em porte e setor dentro do mesmo tema; ii) empresas mais similares tendem a demandar recursos e encontrar dificuldades de acesso ao financiamento para despesa de capital de forma semelhante ${ }^{7}$.

\section{Metodologia e Análise dos Resultados do Programa}

Nesta seção é feito um exame acerca dos resultados apresentados pelo Programa de Subvenção Econômica à Inovação, a partir de um banco de dados obtidos dos resultados finais dos editais pela FINEP, com uma seleção de empresas que obtiveram financiamento e cujos

\footnotetext{
${ }^{7}$ De forma análoga, outros estudos apontam que os níveis de similaridade tecnológica entre empresas geram efeitos diretos e indiretos na performance do esforço inovativo (no caso, em operações de P\&D) em aquisições de empresas com funções complementares (COLOMBO\&RABBIOSI, 2014), além de, pelo ponto de vista geográfico, empresas aglomeradas e similares em um mesmo setor são mais inovativas que empresas não aglorameradas (YILDIZ \&AYKANAT, 2015).
} 
recursos foram liberados até o último trimestre de 2017. O banco de dados abrange uma amostra de 1117 projetos contratados em pouco mais de 1000 empresas em 8 anos de editais lançados (2006 a 2015), tendo aproximadamente R\$ 2,3 bilhões de recursos ${ }^{8}$ desembolsados até o período citado.

Para uma primeira análise descritiva, pode-se observar a classificação das empresas beneficiárias por porte ${ }^{9}$, de acordo com o rendimento anual no ano do edital. De pouco mais de 1000 empresas executoras, 603 empresas são microempresas (54,2\%), 197 foram classificadas como pequena $(17,7 \%)$, enquanto que as médias respondiam por $149(13,4 \%)$ e as grandes, por $163(14,7 \%)$ da amostra. Isso demostra o argumento anteriormente apresentado de que há fortes indícios para o predomínio das MPEs por conta das dificuldades em acessar as modalidades tradicionais de financiamento à inovação.

Se, por um lado, essa evidência indica que as atividades inovativas estimulam e levam as empresas a novos patamares, por outro, mostra os problemas associados à gestão de recursos e necessidade de uma infraestrutura adequada, uma vez que essas empresas estariam pouco preparadas para administrar o volume de recursos recebidos. Ademais, problemas de dependência dos recursos de subvenção para dar continuidade ${ }^{10}$ ao projeto de inovação, como o pagamento de pessoal contratado, tende-se a agravar à medida em que surge atrasos no cronograma de liberação dos recursos e falta de disponibilidade de outros recursos financeiros para manter o andamento das atividades (COSTA et al., 2013; IPEA, 2012).

Partindo para uma análise setorial, pôde-se agregar a amostra em 28 setores, através classificação setorial CNAE 2.0, em variáveis médias (Contrapartida Total/Valor do Projeto e Capital Social), montante (Valor do Projeto, Número de Projetos e Valor Desembolsado) e número de trabalhadores altamente qualificados (Doutores, Mestres e Técnicos de $2^{\circ}$ grau). A descrição dos dados agregados e seus respectivos valores podem ser visualizados na Tabela 1, compreendendo o período de lançamentos dos editais de subvenção econômica.

\footnotetext{
${ }^{8}$ Segundo a amostra, o valor total dos projetos foi de $\mathrm{R} \$ 5,2$ bilhões nos anos compreendidos pelos editais, fazendo com que os recursos liberados respondam por $44 \%$ do total.

${ }^{9}$ A FINEP utiliza a classificação de porte empresarial de acordo com o faturamento bruto anual da empresa no ano de lançamento do edital: até $\mathrm{R} \$ 2,4$ milhões caracteriza microempresa ;de $\mathrm{R} \$ 2,4$ milhões até $\mathrm{R} \$ 16$ milhões caracteriza pequena; de $\mathrm{R} \$ 16$ milhões a $\mathrm{R} \$ 90$ milhões, média empresa; de $\mathrm{R} \$ 90$ milhões a $\mathrm{R} \$ 360$ milhões, médiagrande; e, por fim, a partir de $\mathrm{R} \$ 360$ milhões caracteriza grande empresa.

${ }^{10} \mathrm{O}$ Programa Prime (Primeira Empresa Inovadora), em 2008, tinha como objetivo criar condições de financiamento favoráveis para empresas nascentes de alta intensidade tecnológica. As empresas que conseguissem atingir as metas estabelecidas nos planos de negócios poderiam concorrer a empréstimos do Programa Juro Zero ou por outros programas da Finep, como o INOVAR Semente.
} 
Tabela 1 - Estatística descritiva das variáveis de todos os Setores - 2006 a 2015

\begin{tabular}{cccrrr}
\hline Variáveis & Obs & Média & Erro Padrão & Min & Max \\
\hline $\begin{array}{c}\text { Contrapartida Total/VP1 } \\
(\%)\end{array}$ & 28 & 39,89 & 10,56 & 27,11 & 70,35 \\
\hline $\begin{array}{c}\text { Capital Social } \\
\text { (R\$ milhões) }\end{array}$ & 28 & 541,52 & 1158,48 & 0,48 & 5327,51 \\
\hline $\begin{array}{c}\text { Valor do Projeto } \\
\text { (R \$ milhões) }\end{array}$ & 28 & 182,68 & 216,5 & 3,44 & 727,71 \\
\hline $\mathrm{N}^{\text {o Projetos }}$ & 28 & 39,89 & 54,97 & 1 & 214 \\
\hline $\begin{array}{c}\text { Valor Desembolsado } \\
\text { (R } \$ \text { milhões) }\end{array}$ & 28 & 81,23 & 118,37 & 1,98 & 434,14 \\
\hline Doutores (unid.) & 28 & 20,43 & 29,06 & 0 & 94 \\
\hline Mestres (unid.) & 28 & 26,18 & 37,07 & 0 & 139 \\
\hline Técnicos (unid.) & 28 & 29,68 & 40,31 & 0 & 137
\end{tabular}

Fonte: Elaboração própria a partir de FINEP.

Nota: 1 - Contrapartida/Valor do projeto (R\$ milhões); 2- Capital Social médio do setor (R \$ milhões).

Os dados da Tabela 1 permite a realização de algumas reflexões. O primeiro ponto reforça a relação do esforço empresarial para o projeto através da produção de contrapartida (financeira e não financeira), demostrando que a média dos setores beneficiários do programa ainda possuem predominância de micro e pequenas empresas (valores entre 25 e 41\%). Segundo, mesmo com as variáveis de Capital Social e Valor do Projeto estarem próximas dos valores das grandes empresas, o erro padrão demonstra a heterogeneidade presente, visto que a frequência das observações se encontra mais nas proximidades de valores mínimos do que máximos. Por outro lado, a predominância ${ }^{11}$ dos setores de maior conteúdo tecnológico é notória na relação entre os valores desembolsados e valores dos projetos, e no uso de mão de obra altamente qualificada, especialmente os setores de TIC, informática e eletrônicos, farmacêutico, aeronáutica e atividades de C\&T.

Com o intuito de testar a hipótese de que os setores de maior intensidade tecnológica são os beneficiários majoritários no programa de subvenção econômica e, portanto, maior homogeneidade nas variáveis financeiras e de pessoal contratado no projeto, utilizou-se a análise de cluster (ou agrupamento) para encontrar essas possíveis similaridades entre os setores. Para tanto, a técnica hierárquica aglomerativa escolhida para este artigo foi o Método de Ward. A justificativa de seu uso reside no fato de sua fundamentação estar pautada na

\footnotetext{
${ }^{11}$ De forma mais específica, os setores farmacêutico e de atividades de C\&T foram os que mais utilizaram mão de obra de doutores e mestres, ao passo que os setores de informática, telecomunicações e software utilizaram mais a mão de obra de técnicos de $2^{\circ}$ grau e mestres.
} 
mínima variância entre os grupos e dentro dos grupos que estão sendo formados em cada passo do agrupamento (MINGOTI, 2005), isto é, manter a heterogeneidade entre os grupos, mas tornando os grupos formados mais homogêneos.

A partir da Tabela 2, pode-se notar o agrupamento dos setores de acordo com o Método de Ward a partir das variáveis: número de projetos, valor do projeto e mão de obra qualificada (soma de mestres, doutores e técnicos).

Tabela 2 - Clusters formados a partir dos setores agregados

\begin{tabular}{|c|c|}
\hline Cluster/Setor CNAE & $\begin{array}{c}\mathbf{N}^{\circ} \text { designado para } \\
\text { identificação }\end{array}$ \\
\hline \multicolumn{2}{|l|}{ Cluster 1} \\
\hline Alimentos & 1 \\
\hline Borracha e Plástico & 8 \\
\hline Metais exceto Máquinas e Equipamentos & 11 \\
\hline Aparelhos e Materiais elétricos & 13 \\
\hline Veículos & 15 \\
\hline Aeronaves e peças para aviões & 19 \\
\hline Agricultura e Pecuária & 20 \\
\hline Construção Civil & 23 \\
\hline Comércio varejista de peças e reparo de veículos & 24 \\
\hline \multicolumn{2}{|l|}{$\begin{array}{ll} & \text { Cluster } 2\end{array}$} \\
\hline Bebidas & 2 \\
\hline Têxtil & 3 \\
\hline Couro e Calçados & 4 \\
\hline Celulose e Papel & 5 \\
\hline Impressão & 6 \\
\hline Coque e Derivados do Petróleo & 7 \\
\hline Minerais não-metálicos & 9 \\
\hline Metalurgia & 10 \\
\hline Indústria Extrativa & 21 \\
\hline Geração de eletricidade, água, gás e tratamento de esgoto & 22 \\
\hline Transporte e Armazenagem & 25 \\
\hline \multicolumn{2}{|l|}{ Cluster 3} \\
\hline Químicos & 12 \\
\hline Máquinas e Equipamentos & 14 \\
\hline Aparelhos Médicos & 16 \\
\hline Farmacêuticos & 17 \\
\hline Atividades profissionais, técnicas e científicas & 27 \\
\hline Adm Pública e Serviços & 28 \\
\hline \multicolumn{2}{|l|}{ Cluster 4} \\
\hline Informática e eletrônicos & 18 \\
\hline Informação e Comunicação & 26 \\
\hline
\end{tabular}

Fonte: Elaboração própria a partir de FINEP.

Notas: 1- O setor identificado por 22 na tabela agrega os setores de Eletricidade e gás (35 na divisão CNAE) e Água, Esgoto, Atividades de Gestão de Resíduos e Descontaminação (36 a 39 na divisão CNAE).

2- O setor identificado por 28 na tabela agrega os setores: Administração pública, defesa e seguridade social (84); educação (85); Saúde humana e serviços sociais (86 a 88) e outras atividades de serviços (90 a 99). 
Após a formação do número ótimo de grupo por meio da análise de cluster, pode-se inferir duas importantes análises. A primeira consiste na corroboração parcial da hipótese levantada anteriormente. Há uma composição setorial que possui fortes similaridades entre si, especialmente os grupos 3 e 4, cuja característica predominante são setores baseados em ciência e difusores do progresso técnico ${ }^{12}$, resultado já esperado.

No entanto, a heterogeneidade do Cluster 1 é marcante, dada a combinação de um setor de alta tecnologia (como aeronáutico) com outros de baixa e média-alta intensidades. Uma possível explicação para esse comportamento seria a presença mais notória de grandes empresas nesses setores, que acabam viesando as medidas de similaridade entre os elementos do grupo. Por sua vez, esse viés se deve ao fato de que, nesta modalidade de financiamento, empresas deste porte acabam empregando pouca mão de obra qualificada no projeto e, por consequência, utilizando uma pequena parcela do alto valor aprovado.

O Gráfico 2 apresenta a dispersão entre os grupos formados pela análise de cluster, dado os vetores das variáveis "Valor do Projeto", "Mão de obra altamente qualificada" e "Número de projetos aprovados" e, com isso, alguns pontos importantes são levantados.

Ao analisar o Grupo 3, por mais que haja maiores similaridades entre os setores do cluster, forma-se dois subnúcleos: i) Químicos, Farmacêutico, Atividades de C\&T e Administração Pública; ii) Máquinas e Equipamentos, e Aparelhos Médicos. Apesar dos setores serem prioritariamente de alta intensidade tecnológica (com exceção para o setor de Máquina e Equipamentos), as demandas e os recursos alocados foram de maneiras distintas. Um possível indício estaria na proximidade entre os setores farmacêutico, atividades de C\&T e Administração Pública, visto que, com os recursos de subvenção econômica para os fundos de apoio à pesquisa estaduais (FAPs), geram-se maiores estímulos às empresas do setor farmacêuticos para criar projetos de inovação, por conta da maior difusão do conhecimento científico e tecnológico.

\section{Gráfico 1 - Gráfico de dispersão: Valor do Projeto, M.D.O. qualificada e No Projetos}

\footnotetext{
${ }^{12}$ Para melhor compreensão dessa taxonomia, ver Cavalcante (2014).
} 


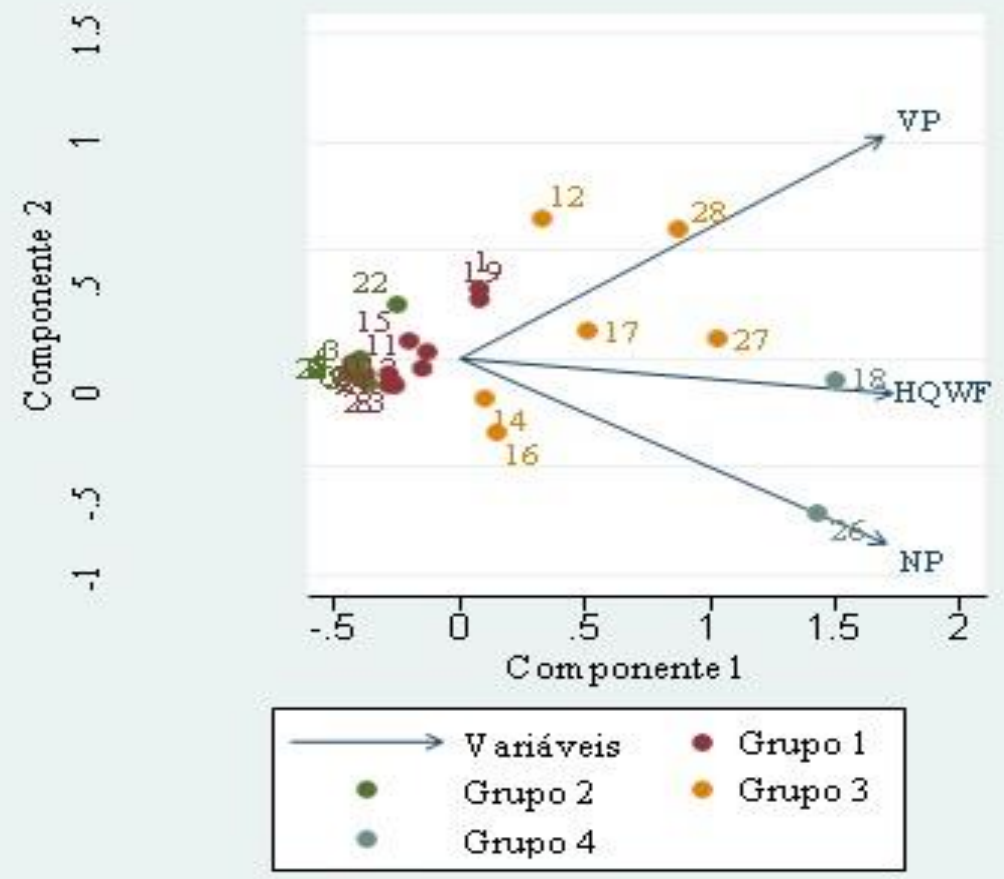

Fonte: Elaboração própria a partir de FINEP.

Notas: 1- Variáveis: VP: valor dos projetos do setor; HQWF: mão de obra qualificada (soma de doutores, mestres e técnicos); NP: número de projetos aprovados no setor.

Ao passo que, no segundo subnúcleo, a difusão do conhecimento tecnológico no setor de Máquinas e Equipamentos pode gerar um maior estímulo às empresas de Aparelhos Médicos para realizar novos projetos de inovação, ainda que estas sejam de setores baseados em ciência e que dependam no mesmo grau de importância dos transbordamentos (spillovers) do conhecimento gerado nas universidades e centros de pesquisa, no caso do artigo pertencentes ao primeiro subnúcleo.

Por fim, ao observar o gráfico, nota-se que, no Grupo 1, o setor aeronáutico está significativamente próximo ao setor alimentício, sendo estes predominados por empresas de grande porte e, por consequência, auxiliando na corroboração do argumento anterior.

\section{Conclusão}

Este artigo procurou identificar as possíveis similaridades setoriais entre as empresas beneficiadas pelo Programa de Subvenção Econômica à Inovação da FINEP. De acordo com os resultados obtidos pela análise de cluster, pode-se inferir que a hipótese de os setores serem mais próximos segundo sua intensidade tecnológica foi confirmada, embora haja 
particularidades nessa afirmação, como foram os casos do setor aeronáutico e do Grupo 3 formado na análise.

Dentro do cluster 3, pode-se observar a heterogeneidade entre os setores de maior intensidade tecnológica, o que abre importantes implicações na elaboração dos editais pela Finep. A primeira dessas implicações reside em editais com temas que, aparentemente, são definidos e alinhados com as políticas industriais vigentes, mas abrangentes ao ponto de englobar uma quantidade significativas de empresas heterogêneas. Evidente exemplo disso são as empresas beneficiárias pelo tema da Saúde, que incluem setores farmacêutico e aparelhos médicos dentro do mesmo edital, visto que apresentaram despesa de custeio diferentes entre os diversos editais lançados.

Evidentemente que o modelo metodológico proposto neste artigo possui limitações, como o fator de agregação das variáveis analisadas, a não distinção dos setores segundo a região geográfica (UF), visto que a subvenção econômica estabelecia um percentual fixo do total de recursos disponível no edital para as regiões Norte, Nordeste e Centro-Oeste. Além disso, por conta de o banco de dados apresentar variáveis somente de resultados de recursos alocados versus utilizados pelas empresas nos editais de subvenção econômica, dificultando a análise a partir de indicadores mais tradicionais de esforço inovativo.

Outro importante ponto refere-se à necessidade de implantação de mecanismos mais efetivos de acompanhamento e avaliação de projetos de subvenção econômica ofertados pela FINEP. Por exemplo, não há evidências concretas de quais foram as inovações desenvolvidas nos projetos terminados, o andamento dos projetos em si, a taxa de sucesso das empresas ao implementar os resultados obtidos com o projeto, os projetos que falharam e os motivos para o insucesso, entre outros (IPEA, 2012).

Por fim, vale ressaltar a necessidade de a FINEP voltar-se à demanda específica de grupo de empresas que, nos critérios de classificação internacional, se encontram no mesmo setor, mas possuem especificidades, necessidades e dificuldades altamente distintas entre si. Uma alternativa para geração de resultados mais positivos pode ser a maior integração dos instrumentos de subvenção e o financiamento reembolsável a taxas subsidiadas, como foi o caso do Programa Prime.

\section{Referências}


AVELLAR, A.P; BITTENCOURT, P.F. Políticas de Inovação: Instrumentos e Avaliação. In: RAPINI, M.S.; SILVA, L.A.; ALBUQUERQUE, E.M. Economia da Ciência, Tecnologia e Inovação: Fundamentos teóricos e a economia global. 1a ed., Editora Prismas, 2017.

BAKKER, G. Money for nothing: How firms have financed $R \& D$-projects since the Industrial Revolution. Research Policy n42, pp.1793-1814, 2013.

CARRIJO, M.C.; BOTELHO, M.R.A Cooperação e inovação: uma análise dos resultados do Programa de Apoio à Pesquisa em Empresas (PAPPE). Revista Brasileira de Inovação, v.12, n.2, pp.417-448, 2013.

CAVALCANTE, A.; RAPINI, M.S.; LEONEL, S.G. Financiamento da Inovação: uma proposta de articulação entre as abordagens pós-keynesiana e neoschumpeteriana. In: RAPINI, M.S.; SILVA, L.A.; ALBUQUERQUE, E.M. Economia da Ciência, Tecnologia e Inovação: Fundamentos teóricos e a economia global. $1^{\mathrm{a}}$ ed., Editora Prismas, 2017.

CAVALCANTE, L.R. Classificações tecnológicas: uma sistematização. Nota Técnica, n.17. Brasília, 2014.

CEPAL. Comissão Econômica para a América Latina e Caribe. Políticas para promover la innovación y el desarrollo tecnológico. Capítulo 6. Relatório Desarrollo Productivo em Economías Abiertas. Chile, 2004.

CGEE e ANPEI. Os novos instrumentos de apoio à inovação: uma avaliação inicial. Brasília: Centro de Gestão e Estudos Estratégicos, 2009.

COSTA, A.C.; SZAPIRO, M.; CASSIOLATO, J.E. Análise da operação do instrumento de subvenção econômica à inovação no Brasil. Conferencia Internacional LALICS, Rio de Janeiro, 2013.

DE NEGRI, F; DE NEGRI, J. A.; LEMOS, M. B. Impactos da ADTEN e do FNDCT sobre o Desempenho e os Esforços Tecnológicos das Firmas Industriais Brasileiras. Revista Brasileira da Inovação, Rio de Janeiro (RJ), 8 (1), p.211-254, janeiro/julho 2008.

FINEP. Manual de Programa de Subvenção Econômica à Inovação Nacional. Rio de Janeiro, 2010 .

Relatório de Gestão 2012. Rio de Janeiro: Finep, 2013.

FREEMAN, C.; SOETE, L. (1997) A Economia da Inovação Industrial. Campinas. Editora da Unicamp, 2006.

HOLLANDA, F. S. M. Financiamento e incentivos à inovação industrial do Brasil. Campinas: Instituto de Economia; Universidade Estadual de Campinas, 2010. Tese de Doutoramento em Economia.

IPEA. A subvenção econômica cumpre a função de estímulo à inovação e ao aumento da competitividade das empresas brasileiras? In: Brasil em desenvolvimento 2011- Estado, planejamento e políticas públicas, v.2, pp.343-358, Rio de Janeiro, 2012.

MINGOTI, S.A. Análise de dados através de Métodos de Estatística Multivariada: uma abordagem aplicada. Editora UFMG, Belo Horizonte, 2005. 
MIRANDA, Z.; MIRRA, E. Trajetórias do Desenvolvimento no Brasil.Revista USP, n.93, pp.33-44. Março/Abril/Maio de 2012.

PAVITT, K. Innovation Process. In: FAGERBERG, J.; MOWERY, D.; NELSON, R. The Handbook of Innovation, Oxford: Oxford University Press. pp. 86-114. 2005.

RAPINI, M. Sistemas Financeiros e o Financiamento a Inovação: Algumas Reflexões para o Brasil. Texto para Discussão $N^{o}$ 367. Belo Horizonte: UFMG/Cedeplar, 2009.

O Financiamento aos Investimentos em Inovação no Brasil. Tese de Doutorado. UFRJ. Rio de Janeiro, 2010. 
Anexo 1 - Estatística descritiva das empresas beneficiadas pela Subvenção Econômica - 2006 a 2017

\begin{tabular}{|c|c|c|c|c|c|c|c|c|}
\hline Setor CNAE & $\begin{array}{c}\text { Média de } \\
\text { Contrapartida } \\
\text { Total/Valor } \\
\text { Projeto }\end{array}$ & $\begin{array}{c}\text { Média de } \\
\text { Capital Social } \\
\text { (R\$ milhões) }\end{array}$ & $\begin{array}{c}\text { Valor do } \\
\text { Projeto } \\
\text { (R\$ milhões) }\end{array}$ & $\begin{array}{l}\text { Quantidade } \\
\text { de Projetos }\end{array}$ & $\begin{array}{c}\text { Valor } \\
\text { Desembolsado } \\
\text { (R\$ milhões) }\end{array}$ & Doutores & Mestres & $\begin{array}{l}\text { Técnicos } \\
\left(2^{\circ} \text { Grau }\right)\end{array}$ \\
\hline Alimentos & 51,68 & $1.637,85$ & 283,42 & 32 & 35,17 & 10 & 17 & 56 \\
\hline Bebidas & 27,11 & 0,48 & 3,44 & 1 & 3,44 & 0 & 4 & 1 \\
\hline Têxtil & 49,14 & 51,94 & 42,88 & 5 & 4,00 & 0 & 0 & 0 \\
\hline Couro e Calçados & 70,35 & 30,90 & 21,90 & 1 & 6,49 & 0 & 0 & 0 \\
\hline Celulose e Papel & 46,40 & $5.327,51$ & 8,79 & 3 & 2,97 & 11 & 5 & 5 \\
\hline Impressão & 28,82 & 12,12 & 4,46 & 2 & 1,98 & 0 & 0 & 0 \\
\hline $\begin{array}{l}\text { Coque e Derivados do } \\
\text { Petróleo }\end{array}$ & 51,89 & 40,21 & 8,20 & 2 & 2,88 & 0 & 0 & 0 \\
\hline Borracha e Plástico & 34,67 & 3,83 & 45,87 & 17 & 31,16 & 7 & 12 & 15 \\
\hline Minerais não-metálicos & 32,60 & 265,06 & 26,00 & 13 & 13,54 & 5 & 4 & 0 \\
\hline Metalurgia & 46,55 & $3.051,60$ & 14,55 & 5 & 6,87 & 0 & 1 & 4 \\
\hline Metais exceto Meq. & 50,24 & 95,32 & 130,42 & 21 & 86,89 & 14 & 15 & 36 \\
\hline Químicos & 41,94 & 935,42 & 469,68 & 50 & 79,13 & 26 & 23 & 44 \\
\hline $\begin{array}{l}\text { Aparelhos e Materiais } \\
\text { elétricos }\end{array}$ & 49,93 & 263,55 & 110,89 & 25 & 26,82 & 9 & 42 & 6 \\
\hline Máquinas e Equipamentos & 33,50 & 198,68 & 165,70 & 52 & 46,14 & 8 & 9 & 94 \\
\hline Veículos & 49,56 & 367,54 & 129,74 & 18 & 47,93 & 7 & 9 & 19 \\
\hline
\end{tabular}




\begin{tabular}{|c|c|c|c|c|c|c|c|c|}
\hline Aparelhos Médicos & 31,61 & 4,31 & 163,06 & 71 & 87,20 & 49 & 23 & 29 \\
\hline Farmacêuticos & 37,20 & 278,03 & 369,65 & 70 & 159,90 & 94 & 67 & 30 \\
\hline Informática e eletrônicos & 34,68 & 56,86 & 727,71 & 193 & 359,82 & 76 & 96 & 137 \\
\hline $\begin{array}{l}\text { Aeronaves e peças para } \\
\text { aviões }\end{array}$ & 35,25 & $1.443,08$ & 249,13 & 24 & 120,97 & 25 & 82 & 6 \\
\hline Agricultura e Pecuária & 33,78 & 4,79 & 56,41 & 14 & 19,63 & 8 & 5 & 21 \\
\hline Indústria Extrativa & 33,02 & 24,06 & 28,35 & 8 & 10,56 & 4 & 5 & 4 \\
\hline $\begin{array}{l}\text { Geração de eletricidade, } \\
\text { água, gás e tratamento de } \\
\text { esgoto }\end{array}$ & 46,20 & 828,02 & 158,34 & 9 & 26,15 & 4 & 7 & 6 \\
\hline Construção Civil & 36,87 & 7,74 & 60,87 & 22 & 34,82 & 1 & 10 & 20 \\
\hline $\begin{array}{l}\text { Comércio varejista de peças } \\
\text { e reparo de veículos }\end{array}$ & 29,15 & 60,82 & 81,02 & 29 & 44,06 & 1 & 1 & 3 \\
\hline Transporte e Armazenagem & 50,61 & 8,00 & 6,41 & 3 & 3,16 & 0 & 0 & 0 \\
\hline Informação e Comunicação & 27,57 & 34,70 & 562,89 & 214 & 334,22 & 62 & 139 & 109 \\
\hline $\begin{array}{l}\text { Atividades profissionais, } \\
\text { técnicas e científicas }\end{array}$ & 29,41 & 103,39 & 536,01 & 113 & 244,55 & 84 & 91 & 125 \\
\hline Adm Pública e Serviços & 27,12 & 26,65 & 649,27 & 100 & 434,14 & 67 & 66 & 61 \\
\hline
\end{tabular}

